\title{
Direct Drive Linear Generator Designs with Aluminium Spacer and Alternate Slot Winding for Wave Energy Conversion System
}

\author{
Naily Akmal Mohd Zamri, Taib Ibrahim, Nursyarizal Mohd Nor \\ Department of Electrical and Electronic Engineering, Universiti Teknologi PETRONAS, Seri Iskandar, 32610, Perak, Malaysia \\ E-mail:naily.akmal_g03220@utp.edu.my,taibib@utp.edu.my,nursyarizal_mnor@utp.edu.my
}

\begin{abstract}
This paper presents the study on direct drive linear generator designs with aluminium spacer and alternate slot winding for wave energy conversion system. The study involved the development of permanent magnet linear generator designs with the variation on aluminium spacer utilization as part of the magnet assembly and alternate slot winding usage instead of conventional winding arrangement. The proposed designs were simulated using Finite Element Method (FEM) software to attain the results on flux distribution, air-gap flux density, and open circuit results. The total weight and material cost of each design were also estimated. These results are significant in finding the acceptable design's alternatives to counter the need of huge and heavy linear generator in wave energy converter system. Comparative studies on simulation results and calculated data were conducted between the alternative and conventional design. It is found out that alternate slot winding design improves the performance of conventional design with no impact on design's weight and material cost while aluminium spacer design yields more significant negative results on the performance than the positive effects in term of design's weight and material cost.
\end{abstract}

Keywords — linear generator; wave energy converter; alternate slot winding; Finite Element Method (FEM)

\section{INTRODUCTION}

Energy challenges faced by the world have given rise to the utilization of renewable energy to attain sustainability in energy as well as to reduce greenhouse gas emission. The average rate of yearly growth for renewable energy utilization is $2.2 \%$ since the year 1990 with biofuel and hydropower as the leading sources [1]. Ocean wave is another promising renewable energy source that has abundant resources with high power density [2] - [4] and highly predictable [3], [4]. High interest on wave energy conversion into useable energy is manifested by the introduction of vast wave energy converter (WEC) system and technology with the earliest wave energy conversion technique patented in the year 1779 [5].

In generating electricity using WEC, generally, there are three stages of conversion involved. Primary conversion implies the extraction of wave motion into WEC body movement in form of water flow or air flow [6]. Next, secondary conversion provides the conversion of mechanical energy in WEC body into useable energy which is electricity and lastly, tertiary conversion gives correction to the generated power before being injected into the grid [6]. This energy conversion in WEC is also known as power take-off (PTO) [7], [8].

This study chose to emphasise and focus on the secondary conversion of WEC system which has a role in energy conversion from mechanical energy to electrical energy. Secondary conversion of WEC basically has two parts; the transmission system and electrical generator [6]. WEC can use two types of electrical generators which are rotary generator and linear generator. Unlike linear generator that can be directly driven by the translational movement of WEC body due to vertical motion of ocean wave, the rotary generator needs to be driven by a transmission system [8], [9]. The transmission system for rotary generator could either be via a hydraulic system of turbine transfer [6], [8], [9]. The advantage of the linear generator over conventional generator led to the acceptance of linear generator in WEC [3]. Generally, linear generator in WEC is operated by having the translator or rotor moving in an upward and downward direction according to the heaving motion of the WEC body that interacts with wave energy such as a buoy. The movements of the translator cause varying magnetic field cutting through the winding and induces a voltage in the system. The general structure of linear generator is as shown in Fig. 1.

Nonetheless, the slow motion of ocean wave leads to the requirement of larger size linear generator in producing specific output power compared to rotary generator [6], [9], [10]. As the result, material cost and weight of the system is also increased. Thus, this paper aims to study the implications of two design alternatives on linear generator 
design in order to reduce the total material cost as well as the weight of the system at a very minimal reduction on the performance of the generator.

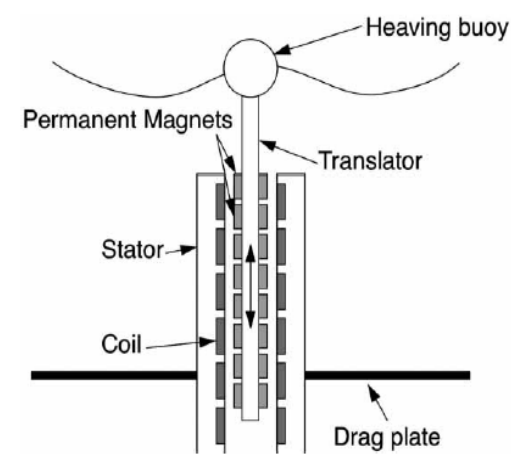

Fig. 1 General construction of linear generator

The two design alternatives are aluminium spacer as part of the magnet assembly and alternate slot winding. As the size of machine increases, the number of magnets used will also increase. Neodymium magnet (NdFeB magnet) that is mostly applied in present electrical machine designs is expensive and increase the usage will affect the material cost greatly especially in long translator design which uses more magnet [4], [11]. Aluminium spacer is proposed to be used by replacing some parts of the magnet as it is cheaper and less dense than $\mathrm{NdFeB}$ magnet. The spacer is usually used with axial magnet arrangement to assemble the same polarity magnet next to each other [12], [13]. It is expected that by reducing the volume of magnets with the introduction of aluminium spacer, the value of induced Back EMF will be decreased [14]. However, reduction in machine weight and material cost are also expected and this could be beneficial in linear generator application in WEC. The effect of aluminium spacer utilization on these quantities need to be analyzed and compared.

Alternate teeth wound technique in the rotary machine was introduced in [15]. Fig. 2 illustrates the design of alternate teeth wound. Nonetheless, its application in the linear machine has not been tested yet. In the preliminary simulation of basic tubular slotted linear generator design, there were several slots that have a low amount of magnetic flux compared to others. By alternating the winding between slots with higher magnetic flux value and slots with lower flux value, more copper coils can be placed to link with the higher flux value.

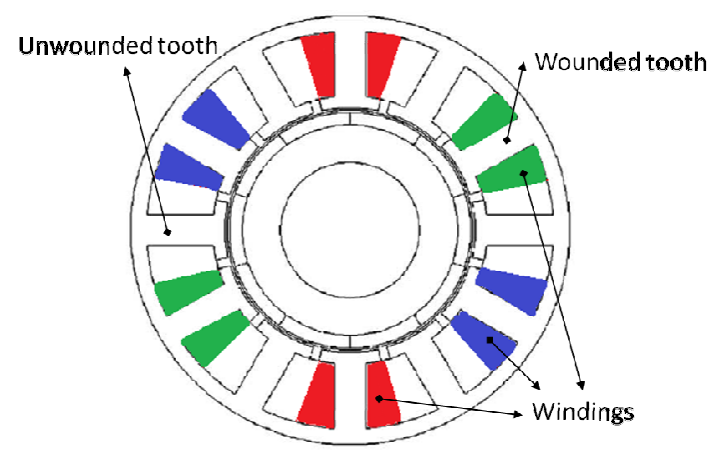

Fig. 2 Alternate teeth wound as in [15]

\section{MATERIAL AND METHODS}

Four generator designs with same topology and dimensions were proposed. Simulation using Finite Element Methods software was performed to attain static condition and open circuit results. Then, weight and material cost of the designs were approximated. Lastly, comparison of the designs was carried out to find the best design alternative.

\section{A. Designs' Topology and Proposed Generator Designs}

The topology of the proposed designs was selected to be longitudinal flux machine with a tubular structure and slotted iron cored. Tubular topology is chosen as the structure yields lesser total power loss and in consequence, produces higher power density [16]. In addition, higher power density and shear stress produced by iron cored topology than air cored able to contribute to smaller size generator [17]. Lastly, longitudinal flux topology is selected because it can be used with a tubular structure unlike transverse flux machine [16].

The selected design's topology was varied into four proposed designs as follows;

- Full Slot Winding with no Aluminium Spacer (control design)

- Full Slot Winding with Aluminium Spacer

- Alternate Slot Winding with no Aluminium Spacer

- Alternate Slot Winding with Aluminium Spacer

Control design utilizes conventional design of tubular linear generator. The design dimensions used in all four proposed designs were kept constant. The values of common dimensions are as shown in Table 1. Fig. 3 shows the 2Dimension images of quarter symmetry (stator-focused) of the four designs while the 3-Dimension image of the designs is as illustrated in Fig. 4.

TABLE I

CONSTANT DESIGN DIMENSIONS

\begin{tabular}{|l|c|}
\hline \multicolumn{1}{|c|}{ Dimension } & Value \\
\hline Air gap diameter, $g$ & $4 \mathrm{~mm}$ \\
\hline Length of stator, $l_{s}$ & $440 \mathrm{~mm}$ \\
\hline Height of stator back iron, $h_{s b i}$ & $15 \mathrm{~mm}$ \\
\hline Width of slot, $w_{s l}$ & $23 \mathrm{~mm}$ \\
\hline Height of slot, $h_{s l}$ & $57 \mathrm{~mm}$ \\
\hline Stator tooth width, $w_{t}$ & $17 \mathrm{~mm}$ \\
\hline Height of magnet, $h_{m}$ & $7 \mathrm{~mm}$ \\
\hline Outer radius of magnet, $r_{m}$ & $56 \mathrm{~mm}$ \\
\hline Depression width (slot opening), $w d$ & $5 \mathrm{~mm}$ \\
\hline Outer radius of stator, $r_{e}$ & $140 \mathrm{~mm}$ \\
\hline Total number of coil, $N_{c}$ & 3240 \\
\hline
\end{tabular}

\section{B. Finite Element Method (FEM) Simulation Parameters}

FEM in Ansys Maxwell platform was used to conduct the simulation. The simulation was carried out in 2-Dimension with the magnetic transient setting. The designs were simulated in two setups which are static condition and open circuit. Designs' flux distribution and air-gap flux density were observed in static condition setup to investigate the effect of design's alternatives on magnetic properties of the designs. In open circuit setup, the translator was set to be moving vertically at a specific speed to attain the results on flux linkage and induced back EMF. Simulation parameters were kept constant for all designs as tabulated in Table 2 . 


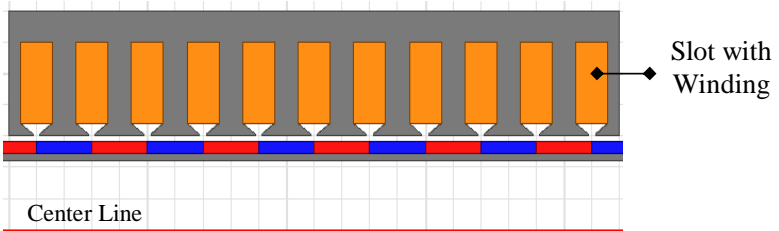

(a)

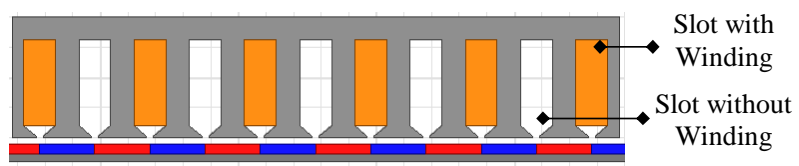

Center Line

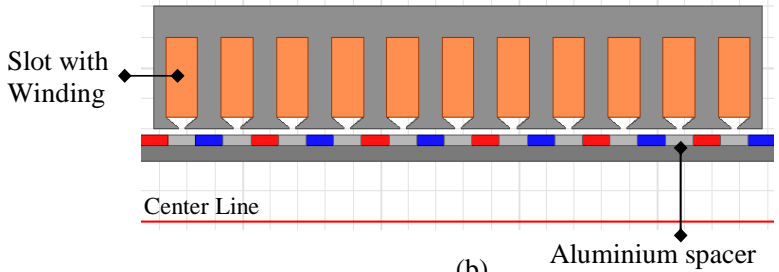

(b)

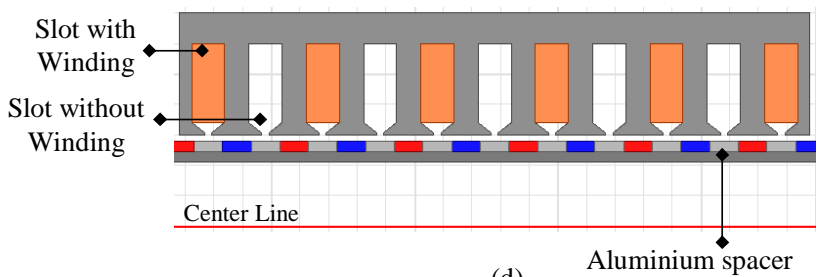

(c)

(d)

Fig. 3. 2-Dimension of quarter symmetry (stator-focused) of, (a) full slot winding with no spacer (control), (b) full slot winding with spacer, (c) alternate slot winding with no spacer and (d) alternate slot winding with spacer

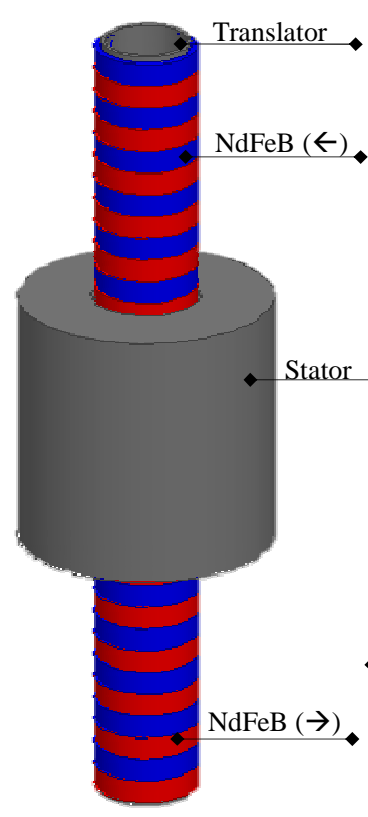

(a)

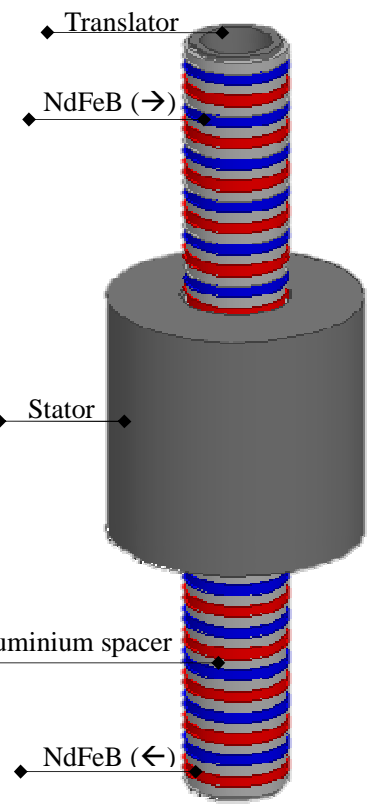

(b)
Fig. 4 3-Dimension of, (a) designs with no aluminium spacer and (b) designs with aluminium spacer

TABLE II

SIMULATION PARAMETERS

\begin{tabular}{|l|c|}
\hline \multicolumn{1}{|c|}{ Simulation Parameter } & Value \\
\hline \multicolumn{2}{|c|}{ Static Condition } \\
\hline Time Open Circuit Condition \\
\hline Length of air-gap line & $0.4 \mathrm{~s}$ \\
\hline \multicolumn{2}{|c|}{ Opm $/ \mathrm{s}$} \\
\hline Speed of translator & $440 \mathrm{~m}$ \\
\hline Distance of translation & Positive z-axis \\
\hline Direction of translation & $1.1 \mathrm{~s}$ \\
\hline Stop time & $0.05 \mathrm{~s}$ \\
\hline Time step &
\end{tabular}

\section{Designs' Weight and Material Cost Calculation}

The total weight and material cost of the designs were computed using measured materials' volume in each design.
The measured volumes were then converted into equivalent material weight and multiplied with the estimated market price of the materials as shown in Table 3.

TABLE III

Current Market Price used in CALCUlation

\begin{tabular}{|l|c|}
\hline \multicolumn{1}{|c|}{ Material } & Price per kg (MYR) \\
\hline $\begin{array}{l}\text { Mild steel (stator back } \\
\text { iron \& translator) }\end{array}$ & 2.00 \\
\hline Copper coil (winding) & 33.91 \\
\hline NdFeB magnet & 250.00 \\
\hline Aluminium (spacer) & 6.40 \\
\hline
\end{tabular}

\section{RESULTS AND DISCUSSION}

Results from the simulation were acquired and designs' weight and material cost were calculated. The data were compiled and compared to investigate the effects of design's alternatives.

\section{A. Flux Distribution and Air-gap Flux Density}

Flux distribution results for all four designs are as shown in Fig. 5. As expected, reduction in the volume of magnet used in designs with aluminium spacers causes the amount of flux available in the designs to be decreased as well. This can be seen in the magnitude of maximum flux line of respective designs in which legend for designs with no spacer has higher maximum magnetic flux line value which is $6.0932 \mathrm{e}-4 \mathrm{~Wb} / \mathrm{m}$ compared to the legend for designs with aluminium spacers which has the value of $4.1353 \mathrm{e}-4 \mathrm{~Wb} / \mathrm{m}$. It can also be deduced that winding arrangement did not have a significant role in the magnitude of the magnetic flux as full slot winding of both with no spacer and with spacer designs have the same magnetic flux value as their respective alternate slot winding design. However, in term of distribution and flow of magnetic flux, all four designs have similar flux path and distribution. 


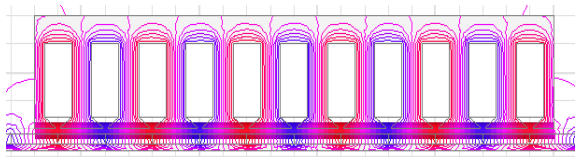

(a)

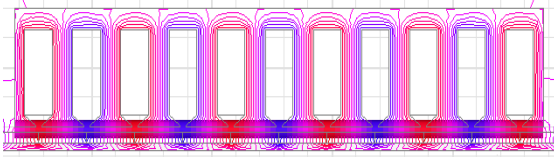

(c)
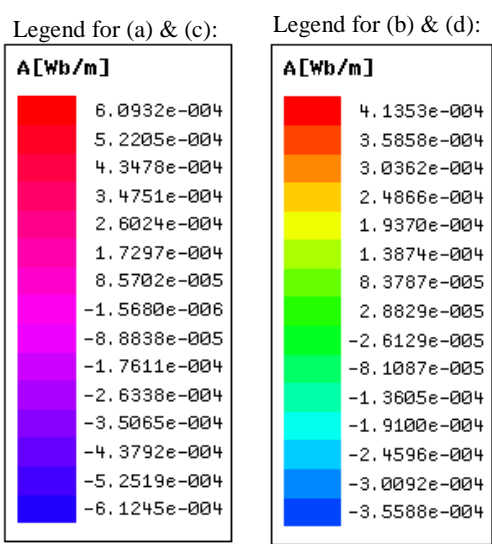

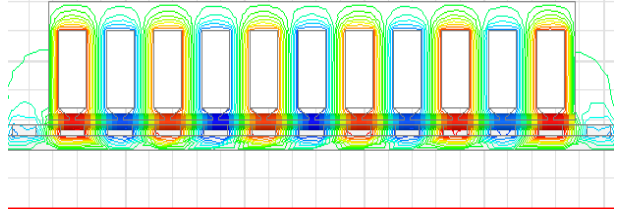

(b)

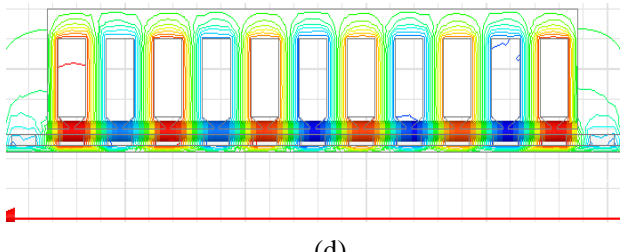

(d)

Fig. 5 Flux distribution of, (a) full slot winding with no spacer (control), (b) full slot winding with spacer, (c) alternate slot winding with no spacer and (d) alternate slot winding with spacer

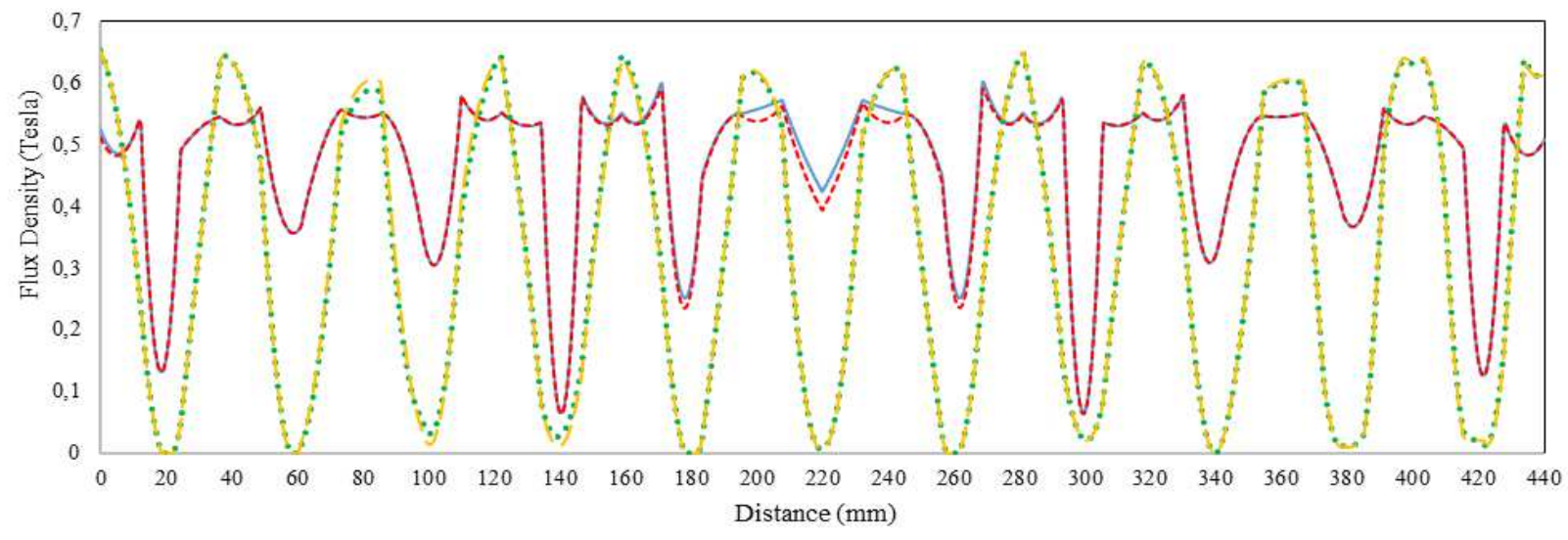

- Full Slot, no spacer $\quad$----- Alternate Slot, no spacer $\quad$....... Full Slot, with spacer $\quad-\quad-$ Alternate Slot, with spacer

Fig. 6 Air-gap flux density of the designs

Fig. 6 shows the air-gap flux density of all four designs against the distance. The distance indicates the length of the stator. The peak values of each waveform indicate the location of magnet parallel to stator teeth which served as good conduction path of flux. The waveforms' negative dips are when the specific parts of magnet assembly are parallel to the stator's slot openings. As observed, the air-gap flux density waveforms of both designs with no spacer are similar while waveforms of both designs with spacer replicate each other. Even though designs with spacer have a higher peak value of flux density, however, if the average value is considered, higher flux density value is produced by designs with no spacer which is $0.5 \mathrm{~T}$ as opposed to $0.4 \mathrm{~T}$ in designs with a spacer. This is because of the stator's length covered with high flux density value of designs with no spacer is longer as observed in Fig. 6.

From both results of flux distribution and air-gap flux density, it can be concluded that by applying aluminium spacer as part of the magnet assembly, the magnetic flux across the generator was affected while winding arrangement has no significant effect on magnetic flux distribution. With this trend in magnetic flux results, it can be predicted that induced back EMF will be highly affected by aluminium spacer utilization compared to the effect due to alternate slot winding arrangement.

\section{B. Flux Linkage and Induced Back EMF}

The results of flux linkage and induced back EMF of the designs are as shown in Fig. 7. Based on the results, flux linkage and induced back EMF waveforms' shapes for all four designs are similar. Nonetheless, a significant difference in term of peak values of designs with no spacer and designs with the spacer can be observed. The average values for flux linkage and induced back EMF results of the designs are as tabulated in Table 4.

TABLE IV

AVERAGE VALUES FOR FLUX LINKAGE AND INDUCED B ACK EMF

\begin{tabular}{|l|c|c|}
\hline \multicolumn{1}{|c|}{ Design } & $\begin{array}{c}\text { Avg. Flux } \\
\text { Linkage }\end{array}$ & $\begin{array}{c}\text { Avg. Induced } \\
\text { Back EMF }\end{array}$ \\
\hline $\begin{array}{l}\text { Full slot winding with no spacer } \\
\text { (control design) }\end{array}$ & $5.139 \mathrm{~Wb}$ & $183.69 \mathrm{~V}$ \\
\hline Full slot winding with spacer & $1.288 \mathrm{~Wb}$ & $39.60 \mathrm{~V}$ \\
\hline $\begin{array}{l}\text { Alternate slot winding with no } \\
\text { spacer }\end{array}$ & $7.103 \mathrm{~Wb}$ & $243.60 \mathrm{~V}$ \\
\hline $\begin{array}{l}\text { Alternate slot winding with } \\
\text { spacer }\end{array}$ & $2.030 \mathrm{~Wb}$ & $70.77 \mathrm{~V}$ \\
\hline
\end{tabular}



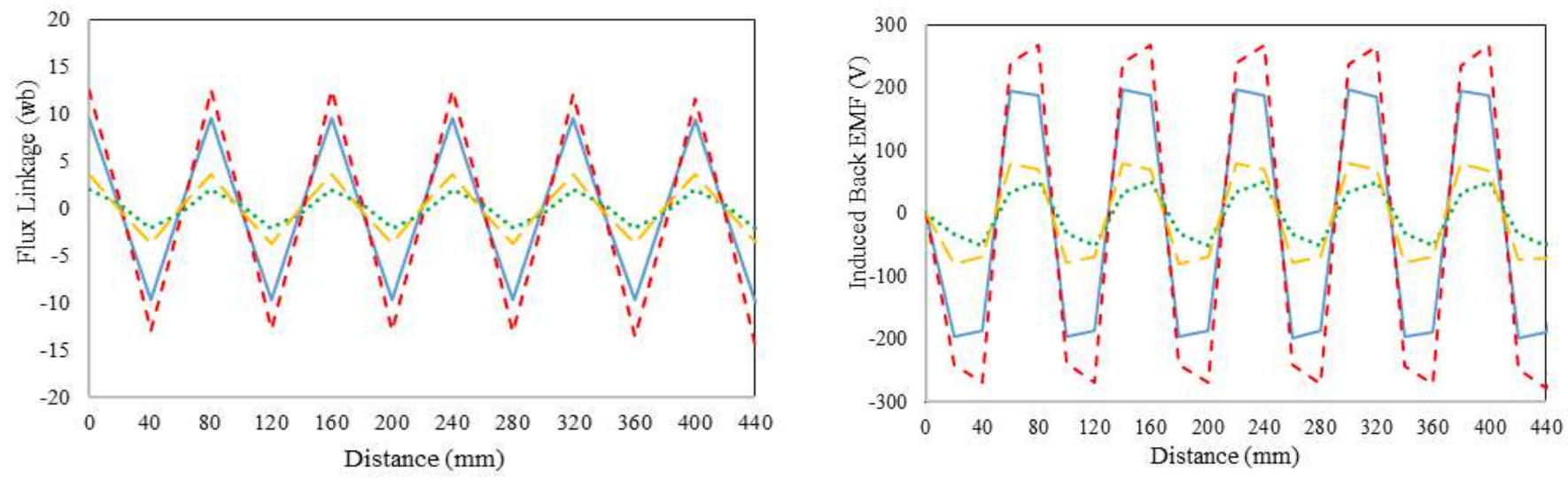

Full slot, no spacer _ _ - - Alternate slot, no spacer $\quad$......... Full slot, with spacer $\quad$ - - Alternate slot, with spacer

Fig. 7. Results of, (a) Flux Linkage and (b) Induced Back

TABLE V

MATERIAL Volume, WeIGHT, AND Cost OF THE DESIGNS

\begin{tabular}{|c|c|c|c|c|c|c|c|c|c|c|c|c|}
\hline \multirow{2}{*}{ Material } & \multicolumn{3}{|c|}{$\begin{array}{c}\text { Full slot, no spacer } \\
\text { (control) }\end{array}$} & \multicolumn{3}{|c|}{ Full slot, with spacer } & \multicolumn{3}{|c|}{ Alternate slot, no spacer } & \multicolumn{3}{|c|}{ Alternate slot, with spacer } \\
\hline & $\begin{array}{l}\text { Volum } \\
\text { e }\left(\mathbf{m}^{\mathbf{3}}\right)\end{array}$ & $\begin{array}{l}\text { Weight } \\
\text { (kg) }\end{array}$ & $\begin{array}{c}\text { Cost } \\
(\text { MYR) }\end{array}$ & $\begin{array}{l}\text { Volum } \\
\text { e }\left(\mathbf{m}^{3}\right)\end{array}$ & $\begin{array}{c}\text { Weight } \\
\text { (kg) }\end{array}$ & $\begin{array}{c}\text { Cost } \\
\text { (MYR) }\end{array}$ & $\begin{array}{l}\text { Volum } \\
\text { e }\left(\mathbf{m}^{3}\right)\end{array}$ & $\begin{array}{c}\text { Weight } \\
\text { (kg) }\end{array}$ & $\begin{array}{c}\text { Cost } \\
\text { (MYR) }\end{array}$ & $\begin{array}{l}\text { Volum } \\
\text { e }\left(\mathbf{m}^{3}\right)\end{array}$ & $\begin{array}{c}\text { Weight } \\
\text { (kg) }\end{array}$ & $\begin{array}{l}\text { Cost } \\
\text { (MYR) }\end{array}$ \\
\hline Mild steel & 0.016 & $\begin{array}{c}124.81 \\
3\end{array}$ & 249.63 & 0.016 & $\begin{array}{c}125.04 \\
3\end{array}$ & 250.09 & 0.016 & $\begin{array}{c}124.81 \\
3\end{array}$ & 249.63 & 0.016 & $\begin{array}{l}125.04 \\
3\end{array}$ & 250.09 \\
\hline $\begin{array}{l}\text { Copper } \\
\text { coil }\end{array}$ & 0.0043 & 37.806 & $\begin{array}{c}1281.9 \\
9\end{array}$ & 0.0043 & 37.806 & $\begin{array}{c}1281.9 \\
9\end{array}$ & 0.0043 & 37.806 & $\begin{array}{c}1281.9 \\
9\end{array}$ & 0.0043 & 37.806 & $\begin{array}{c}1281.9 \\
9\end{array}$ \\
\hline $\begin{array}{l}\mathrm{NdFeB} \\
\text { magnet }\end{array}$ & 0.0031 & 23.553 & $\begin{array}{c}5888.1 \\
3\end{array}$ & 0.0016 & 11.776 & $\begin{array}{l}2944.0 \\
7\end{array}$ & $\begin{array}{c}0.0031 \\
4\end{array}$ & 23.553 & $\begin{array}{c}5888.1 \\
3 \\
\end{array}$ & 0.0016 & 11.776 & $\begin{array}{c}2944.0 \\
7\end{array}$ \\
\hline $\begin{array}{l}\text { Aluminiu } \\
\mathrm{m}\end{array}$ & 0 & 0 & 0 & 0.0016 & 4.3641 & 27.93 & 0 & 0 & 0 & 0.0016 & 4.3641 & 27.93 \\
\hline Total Cost & \multicolumn{3}{|c|}{ 7419.74 MYR } & \multicolumn{3}{|c|}{ 4504.07 MYR } & \multicolumn{3}{|c|}{ 7419.74 MYR } & \multicolumn{3}{|c|}{ 4504.07 MYR } \\
\hline $\begin{array}{l}\text { Translato } \\
\text { r Weight }\end{array}$ & \multicolumn{3}{|c|}{$39.378 \mathrm{~kg}$} & \multicolumn{3}{|c|}{$32.195 \mathrm{~kg}$} & \multicolumn{3}{|c|}{$39.378 \mathrm{~kg}$} & \multicolumn{3}{|c|}{$32.195 \mathrm{~kg}$} \\
\hline $\begin{array}{l}\text { Total } \\
\text { Weight }\end{array}$ & \multicolumn{3}{|c|}{$186.171 \mathrm{~kg}$} & \multicolumn{3}{|c|}{$178.989 \mathrm{~kg}$} & \multicolumn{3}{|c|}{$186.171 \mathrm{~kg}$} & \multicolumn{3}{|c|}{$178.989 \mathrm{~kg}$} \\
\hline
\end{tabular}

The average values of full slot winding and alternate slot winding with spacer are too small compared to designs with no spacer. Reduction of average induced back EMF value in full slot winding with a spacer and alternate slot winding with a spacer is around $75 \%$ and $60 \%$ respectively when being compared to control design. However, when comparing the effect of winding arrangement on induced back EMF and flux linkage, alternate slot winding designs average values are higher than their respective full slot winding designs.

Alternate slot winding with no spacer design recorded the highest average value of induced back EMF and the value is higher than control design by $33 \%$. Even though other dimensions are kept constant in these two designs, by implementing alternate winding arrangement, the value of induced back EMF can be slightly increased. This result is contradicting from the finding in [18] as the designs in [18] are not fully optimized, unlike these designs that already undergone optimization. Thus, it can be deduced that, as predicted in flux distribution and flux density results, implementation of aluminium spacer significantly reduces the performance of the designs. In contrast, by implementing alternate slot winding arrangement, the performance is improved

\section{Weight and Material Cost Calculation}

The volume, calculated weight and cost of materials for each design are as shown in Table 5. The designs' stator and translator core are made up of the same material which is mild steel.

As expected, the introduction of aluminium spacer minimizes the translator weight and total material cost due to the density and material cost of aluminium which is lower than NdFeB magnet. Lower translator weight is favorable in a linear generator for WEC as it can be translated easier by the slow heaving motion of the wave. Compared to control design, $50 \%$ of $\mathrm{NdFeB}$ magnet volume was replaced with aluminium in designs with a spacer. However, as the total price of $\mathrm{NdFeB}$ magnet is accountable for only $79 \%$ of the total material cost, the effective reduction of material cost 
due to aluminium spacer introduction is only $39 \%$ ( 0.79 out of $50 \%$ ). In term of weight, only $60 \%$ of total translator's weight is from magnet assembly. Thus, the effective decrement of translator's weight with the introduction of aluminium spacer is not too significant which is only $17 \%$ of reduction.

Utilization of alternate slot winding arrangement in designs did not give any effect on the total weight and material cost of the designs.

\section{Designs Comparison}

Table 6 tabulates the compilation of data to compare the overall benefits and drawbacks of the designs in term of flux distribution, air gap flux density, open circuit results (flux linkage and induced back EMF), total material cost and designs' weight.

TABLE VI

DATA FOR DESIGNS' COMPARISON

\begin{tabular}{|c|c|c|c|c|}
\hline Comparison & $\begin{array}{c}\text { Full slot, } \\
\text { no spacer } \\
\text { (control) }\end{array}$ & $\begin{array}{c}\text { Full slot, } \\
\text { with } \\
\text { spacer }\end{array}$ & $\begin{array}{c}\text { Alternate } \\
\text { slot, no } \\
\text { spacer }\end{array}$ & $\begin{array}{c}\text { Alternate } \\
\text { slot, with } \\
\text { spacer }\end{array}$ \\
\hline $\begin{array}{c}\text { Maximum } \\
\text { flux } \\
\text { distribution } \\
\text { value } \\
\text { (Wb / m) }\end{array}$ & $6.09 \mathrm{e}-4$ & $4.13 \mathrm{e}-4$ & $6.09 \mathrm{e}-4$ & $4.13 \mathrm{e}-4$ \\
\hline $\begin{array}{c}\text { Avg. airgap } \\
\text { flux density } \\
\text { (T) }\end{array}$ & 0.5 & 0.4 & 0.5 & 0.4 \\
\hline $\begin{array}{c}\text { Avg. flux } \\
\text { linkage (Wb) }\end{array}$ & 5.139 & 1.288 & 7.102 & 2.030 \\
\hline $\begin{array}{c}\text { Avg. induced } \\
\text { back EMF } \\
\text { (V) }\end{array}$ & 183.69 & 39.60 & 243.60 & 70.77 \\
\hline \begin{tabular}{c} 
Weight (kg) \\
\hline $\begin{array}{c}\text { Material Cost } \\
\text { (MYR) }\end{array}$
\end{tabular} & 7419.74 & 4504.07 & 7419.74 & 4504.07 \\
\hline
\end{tabular}

In term of flux distribution, utilization of aluminium spacer in the designs reduced the maximum flux distribution value by $31 \%$. This reduction is due to the decrement in the volume of magnet that is available in the designs as aluminium spacer is used as part of the magnet assembly. No effect on flux distribution value is recorded with the introduction of alternate slot winding as the magnetic properties of the designs are unaffected. The similar trend is observed on the result of air gap flux density. Reduction of $20 \%$ from the average value is calculated when aluminium spacer is utilized. From these static condition results, it can be concluded that magnetic value in the designs are altered as aluminium spacer replaced some part of magnet assembly while the value is not affected by the utilization of alternate slot winding. Reduction in flux distribution and air gap flux density of the designs will influence the open circuit quantities as well due to the linear relationship of flux linkage value with a flux density of the design.
Comparing designs with a spacer and their counterpart designs with no spacer, the drop in average flux linkage and induced back EMF is around $75 \%$ and $71 \%$ for full slot winding and alternate slot winding respectively. From these percentages, it can be realized that reduction of about $70 \%$ in term of open-circuit performance is expected when $50 \%$ of the magnets in magnet assembly was substituted with aluminium spacer. From this result, it can be concluded that utilization of aluminium spacer as part of magnet assembly affects the open-circuit performance greatly.

The utilization of aluminium spacer gives benefit in term of the total weight and material cost of the design. The overall weight is decreased by $4 \%$ while the total material cost is minimized by $39 \%$. However, comparing the total magnet replacement by aluminium spacer which is $50 \%$, the reduction in these two quantities is not significant. With the addition of a percentage of decrement in the open circuit results which is higher than the reduction in material total weight and material cost as well as the reduction in the magnetic values of the designs, this alternative of using aluminium spacer provides more significant disadvantages in the designs than advantages.

Conversely, the use of alternate slot winding in designs raised the average values of flux linkage and induced back EMF. As mentioned previously, alternate slot winding with no spacer designs increased both quantities by around $35 \%$ from control design. Even in designs with a spacer, open circuit results were improved with the utilization of alternate slot winding. In term of the drawbacks on the usage of alternate slot winding, the drawbacks are not from the total weight or total material cost of the designs. However, proper calculation onto the suitable number of coil turns per slot needs to be conducted so the winding can fit and fill properly into the slot. Thus, alternate slot winding utilization provides advantages on the design by increasing the opencircuit results while maintaining the flux distribution and air gap flux density value as well as having the same total weight and material cost as conventional full slot winding designs.

Based on the comparison of flux distribution value, air gap flux density, open circuit results, total material cost and designs' weight, it can be concluded that usage of aluminium spacer in the design causes greater negative effects than gains. On the contrary, the utilization of alternate slot winding arrangement is capable to increase the open circuit parameters of the design. This can be benefited in having slightly smaller size generator than full slot winding design in achieving the same desired induced back EMF. From these results, alternate slot winding with no spacer design is selected to be the most efficient design than other proposed designs.

\section{CONCLUSION}

Four designs with variations in term of the utilization of aluminium spacer and alternate slot winding arrangement were introduced and the simulation results for the designs were discussed in this paper. From the results, it is found out that the usage of aluminium spacer influences the magnitude of magnetic flux and thus reduces the amount of flux linkage and induced back EMF. The advantages in design's weight 
and material cost due to the usage of aluminium spacer are trivial compared to the drawbacks. It can also be concluded that alternate slot winding arrangement does not affect the magnitude of flux in the design however as the winding arrangement concentrates winding on the slot with high flux magnitude, the linkage of the flux and coil increases and thus increases the induced back EMF. More work will be conducted to validate the simulation results through experiment.

\section{ACKNOWLEDGMENT}

The authors would like to thanks the Universiti Teknologi PETRONAS (UTP) and Kementerian Pendidikan Tinggi Malaysia (KPT) for the awarded Fundamental Research Grant Scheme.

\section{REFERENCES}

[1] Key Renewables Trends - Excerpt From : Renewables Information [Online]. International Energy Agency (IEA), 2016, Available: http://www.iea.org/publications/freepublications/publication/KeyRen ewablesTrends.pdf

[2] M. Bilgili, A. Ozbek, B. Sahin, and A. Kahraman, "An Overview of Renewable Electric Power Capacity and Progress in New Technologies in the World," in Renewable and Sustainable Energy Reviews, vol. 49, pp. 323-334, 2015.

[3] K. S. R. Rao, T. Sunderan, and M. R. Adiris, "Performance and Design Optimization of Two Model Based Wave Energy Permanent Magnet Linear Generators," in Renewable Energy, vol. 101, pp. 196-203, 2017.

[4] J. Prudell, M. Stoddard, E. Amon, T. K. A. Brekken, and A. v. Jouanne, "A Permanent-Magnet Tubular Linear Generator for Ocean Wave Energy Conversion," in IEEE Transactions on Industry Applications, vol. 46, no. 6, pp. 2392-2400, 2010.[5] E. E. Shpilrain, Renewable Energy Sources Charged With Energy from the Sun and Originated from Earth-Moon Interactions - Volume II. EOLSS Publishers Company Limited, 2009.

[6] I. López, J. Andreu, S. Ceballos, I. Martínez de Alegría, and I. Kortabarria, "Review of Wave Energy Technologies and the Necessary Power-Equipment," in Renewable and Sustainable Energy Reviews, vol. 27, pp. 413-434, 2013.
[7] R. Kempener and F. Neumann, Wave Energy: Technology Brief [Online]. International Renewable Energy Agency, 2014, Available: http://www.irena.org/

[8] B. Drew, A. R. Plummer, and M. N. Sahinkaya, "A Review of Wave Energy Converter Technology," in Proceedings of the Institution of Mechanical Engineers, Part A: Journal of Power and Energy, vol. 223, no. 8, pp. 887-902, 2009.

[9] M. A. Mueller, H. Polinder, and N. Baker, "Current and Novel Electrical Generator Technology for Wave Energy Converters," in 2007 IEEE International Electric Machines \& Drives Conference, pp. 1401-1406, 2007.

[10] T. Xia, H. Yu, Z. Chen, L. Huang, X. Liu, and M. Hu, "Design and Analysis of a Field-Modulated Tubular Linear Permanent Magnet Generator for Direct-Drive Wave Energy Conversion," in IEEE Transactions on Magnetics, vol. PP, no. 99, pp. 1-1, 2017.

[11] H. Polinder, B. C. Mecrow, A. G. Jack, P. G. Dickinson, and M. A. Mueller, "Conventional and Tfpm Linear Generators for Direct-Drive Wave Energy Conversion," in IEEE Transactions on Energy Conversion, vol. 20, no. 2, pp. 260-267, 2005.

[12] T. Parel, M. D. Rotaru, J. K. Sykulski, and G. E. Hearn, "Optimisation of a Tubular Linearmachine with Permanent Magnets for Wave Energy Extraction," in The International Journal for Computation and Mathematics in Electrical and Electronic Engineering, vol. 30, no. 3, pp. 1056-1068, 2011.

[13] J. Wang, G. W. Jewell, and D. Howe, "Design Optimisation and Comparison of Tubular Permanent Magnet Machine Topologies," in IEE Proceedings - Electric Power Applications, vol. 148, no. 5, pp. 456-464, 2001.

[14] J. Wang and D. Howe, "Design Optimization of Radially Magnetized, Iron-Cored, Tubular Permanent-Magnet Machines and Drive Systems," in IEEE Transactions on Magnetics, vol. 40, no. 5, pp. 3262-3277, 2004.

[15] D. Ishak, Z. Q. Zhu, and D. Howe, "Comparison of Pm Brushless Motors, Having Either All Teeth or Alternate Teeth Wound," in IEEE Transactions on Energy Conversion, vol. 21, no. 1, pp. 95-103, 2006.

[16] C. A. Oprea, C. S. Martis, F. N. Jurca, D. Fodorean, L. Szabo, and L. Szabó, "Permanent Magnet Linear Generator for Renewable Energy Applications: Tubular Vs. Four-Sided Structures," in 2011 International Conference on Clean Electrical Power (ICCEP), pp. 588-592, 2011.

[17] A. S. Mcdonald, M. A. Mueller, and H. Polinder, "Structural Mass in Direct-Drive Permanent Magnet Electrical Generators," in IET Renewable Power Generation, vol. 2, no. 1, pp. 3-15, 2008.

[18] N. A. M. Zamri, T. Ibrahim, and N. M. Nor, "Design and Modeling of Generator for Wave Energy Conversion System in Malaysia," in International Journal of Simulation Systems, Science \& Technology, vol. 17, no. 41, pp. 23.1 - 23.6, 2016. 